\title{
Determinants of Inflation: Evidence from Pakistan using Autoregressive Distributed Lagged Approach.
}

\author{
Niaz Hussain Ghumro ${ }^{1}$ \\ Assistant Professor Sukkur Institute of Business Administration, Pakistan \\ Pervaiz A. Memon ${ }^{2}$ \\ Assistant Professor Sukkur Institute of Business Administration, Pakistan
}

\begin{abstract}
Controlling inflation is one of the biggest challenges faced by the macroeconomic policymakers in Pakistan. This research article is aimed at highlighting the main sources of inflation in the economy of Pakistan using an autoregressive distributed lag model for the period from 1980 to 2012. Findings of this study reveal that the one percent rise in the long run money supply, exchange rate, total reserve, and the gross national expenditure change inflation by $0.16,2.12,0.36$, and 1.78 percent points respectively. The Error Correction model with negative sign remains statistically significant with approximate $81 \%$ speed of adjustment to restore the equilibrium in the long run, which shows the quick convergence.
\end{abstract}

Keywords: Determinants of Inflation, Money Supply, Exchange Rate, Total Reserves ARDL.

https://doi.org/10.30537/sijmb.v2i1.86

1 niaz_ghumro@iba-suk.edu.pk

2 pervaiz@iba-suk.edu.pk

E-ISSN: 2410-1885; $P$ - ISSN: 2313-1217 @ 2015 Sukkur Institute of Business Administration - All rights reserved 


\section{Introduction}

The continual upward movement in price level in the economy is called inflation. During the inflationary period money loses its value. The problem of soaring inflation has critical significance in Pakistan economy with social implications. According to economics theory, the inflation rate has direct relation to gross domestic product (GDP), fiscal deficit, government expenditure, tax revenue, money supply, exports, exchange rate, prices of imports, interest rate and others.

Many ways have been identified to measure the inflation. In Pakistan, inflation is usually measured either with the proxy of Gross Domestic Product Deflator (GDP Deflator), which shows overall inflation in the economy or with the Consumer Price Index (CPI) that shows the movement in the general price level of basket of goods and services of consumers' products ( Asian Bank Report, 2012). Furthermore, according to (Selden 1959), the inflation is categorized as cost-push and demand-pull based on its cause of movement in overall general price level in the economy.

\section{COST-PUSH INFLATION}

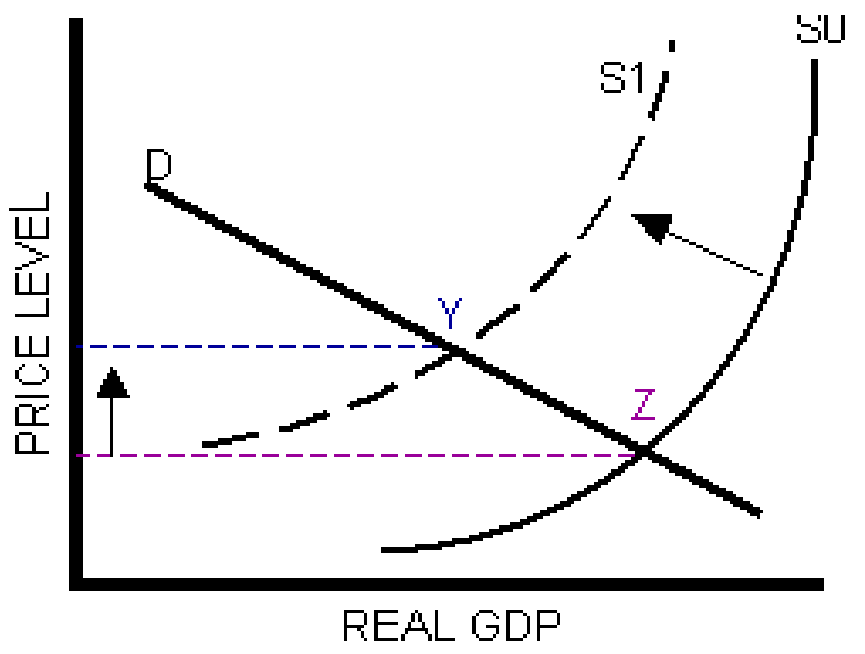

Figure 1

Cost-push inflation prevails when general prices of input factors increase. The rise in the prices of raw material or increase in the rapid wage invites the cost-push inflation. The rise in imported oil's price in year 2012 describes the cost-push inflation (illustrated in figure-1).The rise in energy prices leads to the rise in cost of production and transportation of goods and services in the economy. The higher production cost lowers the aggregate supply (from $\mathrm{S}_{0}$ to $\mathrm{S}_{1}$ ) that causes rise in price level and equilibrium returns back from $\mathrm{Z}$ to $\mathrm{Y}$. 


\section{DEMAND-PULL INFLATION}

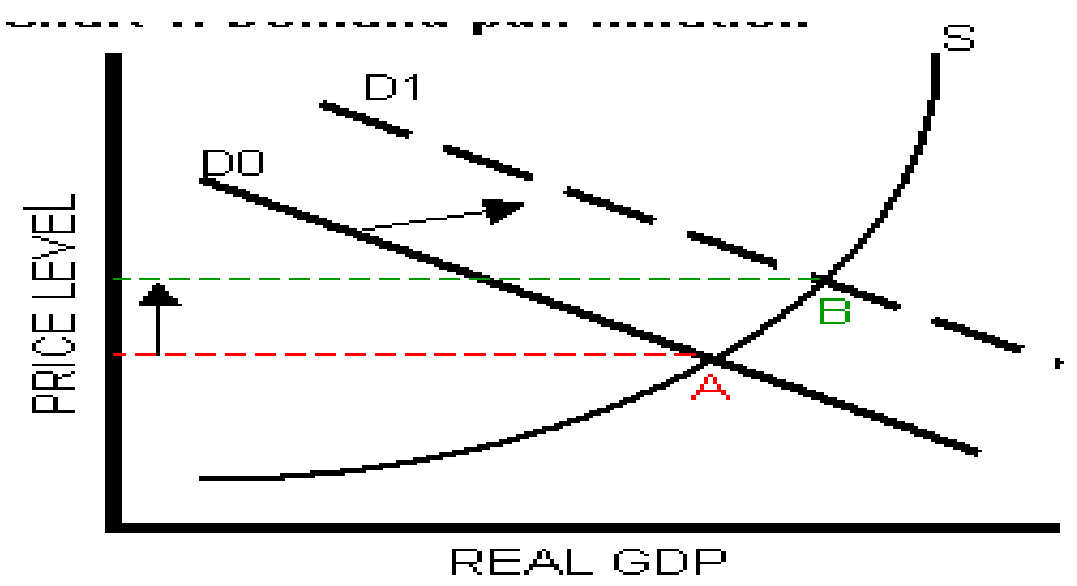

Figure 2

On the other hand, Demand-pull inflation occurs when aggregate demand for goods and services increase more sharply than the production capacity in the overall economy. When central bank increases money supply the aggregate demand might takes a potential shock (Figure-2). The increase in money supply will shift demand curve from $\mathrm{D}_{0}$ to $\mathrm{D}_{1}$. Since businesses cannot increase their production and no change in the supply (S) in the short run, the rise in the prices occurs and the equilibrium point shifts from point A to point B.

According to the Pakistan Bureau of Statistics, the recorded inflation rate was 5.13\% in May, 2013 and historically averaged to 8.03\% from 1957 to 2013. Prices rise slowly in India than Pakistan which is alarming for Pakistan's economy. The most important categories of CPI in Pakistan are described in the Figure-3.It depicts that food and non-alcoholic beverages keeps $35 \%$ of the total weight and holds the highest portion of CPI. Housing, water, electricity, gas and fuels has $29 \%$ weight age while clothing and footwear hits to $8 \%$, and transport reaches to $7 \%$. The figure-3 also reports furnishings and household equipment to $4 \%$, education to $4 \%$, communication to $3 \%$ and health to $2 \%$. The remaining other categories amount $8 \%$ which includes culture, hotels, tobacco, alcoholic beverages, and others. 


\section{Category-wise percentage of inflation in Pakistan}

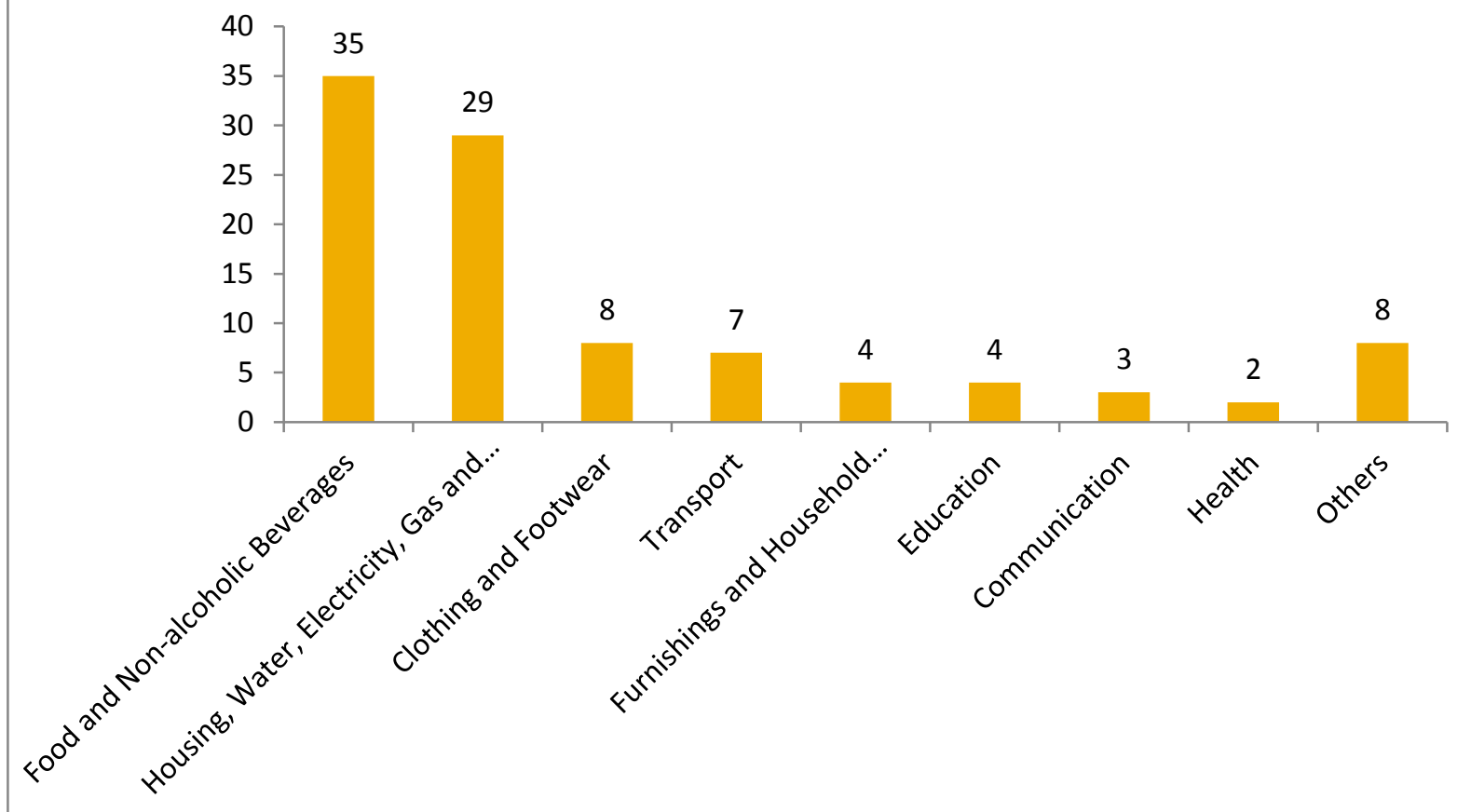

Figure 3

Source: Federal Statistical Bureau of Pakistan

The inflation in an economy affects Depositors' real value or purchasing power and savings. Actuarial, financial, fixed value assets and saving account lessen in real value during the time of inflation. Debtors enjoy a lot from the loan of creditors in the time of unanticipated inflation. Particularly, low rates of inflation are prerequisites for the macroeconomic management in developing and under-developed countries.

When prices rise, the inflation in an economy axes depositors by lowering their purchasing power and savings. The inflation has many adverse effects for the economy. Firstly, it smashes peoples' purchasing power, shrinks economic growth, rooms macroeconomic instability, whereas the inflationary environment gives birth to many dubieties. Secondly, it throws a negative effect on the poverty, increases overall prices, and detriments consumption basket of the poor which was significantly abridged in each inflationary round. Thirdly, it can hurt an economy's stability by an over-valuation of the domestic currency and a consequent appreciation in exchange rate has also regressive impact upon exports.

Especially, in developing and under-developed countries such as Pakistan and Nigeria; the households' living cost is soared due to inflation. Due to higher inflation, food consumption 
is reduced by households that lead to malnutrition which results productivity loss of about 10 percent in earnings whereas GDP sheds of two to three percent into badly impacted countries (Alderman. H, 2005). "High inflation reduces the benefits of growth and worsens off the poor" (Easterly. W; 2003). More than fifty percent of budget of low wagers is consumed to food. There are ample factors adding inflationary effect in Pakistan such as population growth and per capita income. There is a serious lack of strategic management in the country, due to which the price level rises; if there is shortage in supply or increase in demand. A variety of edible and non-edible items are merchandised illegally on the borders of Pakistan, Afghanistan and Iran, which makes significant financial loss to the country in the form of public receipts that might be accumulated in terms of taxation (Sharif et al., 2000).

According to the report of Asian Development Bank (2012), the reserves declined in first mid of FY2012 and economic situation worsened. Furthermore, both food and general inflation rose after decline of reserve, and imports contracted while exports stagnated. Thus, inflation is expected to rise to a level near to 9 percent.

Given the importance to curbing inflation in the economic development of the country, this present study fills the gap by investigating the impact of total reserves and gross national expenditure on inflation and tracing out causal relations of macroeconomic variables with inflation.

Remaining paper is organized as follows. Second section of this paper discusses the literature review followed by the section three that describes the data and model. Section four deals with methodology and section five discusses results on econometric criterion followed by section six that concludes this study.

\section{Literature Review}

There are ample research articles determining the factors affecting inflation authored by many scholars at national as well as international level. They are totally different from one another in terms of sampling unit, time period, sample size or variables' selection. In this section, the little account of work done in this area is given.

According to Empirical studies external and domestic factors cause inflation. The determinants of inflation are mainly monetary, demand, cost push, and foreign in nature. (Hasan and Alogeel 2008) analyze that foreign inflation affects inflation in the long run, whereas in short run, inflation is affected by money supply and demand in Saudi Arabia and Kuwait. (Khan and Gill 2010) gestured that world prices affect inflation more than monetary sources in Saudi Arabia. (Taslim 1980) conducts a study to explain the inflationary process of Bangladesh through regression models and finds that money supply with lagged one year has significant positive impact on inflation. However, introducing a new wage variable in the list 
of previous independent variables, shows striking fall in statistical significance of coefficients of other variables in the regression model.

(Papi and Lim 1997) analyze time series data from 1970 to 1995 for determinants of inflation in Turkey and apply Johansen Co-integration technique to evaluate the output. The output evidences that wages, money, and import and export prices have significant positive effect on inflation. Moreover, exchange rate shows adverse impact on inflation in Turkey. (Laryea and Sumaila 2001) conduct the study to identify the main factors of inflation for Tanzanian economy for the long and short run. They find that monetary factors and output are short run determinants while exchange rate for long run.

(Hussain 2005) and (Khan 2006) suggest that inflation from three to six percent leaves positive effect on economy, since production and investment are encouraged and growth in wages are allowed. Moreover, when inflation crosses the above limit, negative effects are produced and the medium of exchange, money, decreases in its value. This creates panic in the value of losses and gains of lenders and borrowers as well as sellers and buyers. The investment and savings are discouraged. The discouraged investment lowers the economic growth and saving and invites the inflation that cuts down the return of the financial assets.

(Pahlavani and Rahimi 2009) used ARDL model to find out long run inflationary factors in Iran by adopting time series from 1971 to 2006 . This study explores that GDP, money supply, change in domestic prices, exchange rate, and foreign prices affect the economy of Iran and all variables under study have positive significant influence on inflation (local prices).

(Abidemi and Malik 2010) explore the factors of inflation dynamically and simultaneously inter- relationship in Nigeria. The time series data from 1970 to 2007 is evaluated by Johansen Co-integration technique and (ECM) Error Correction Model. The results slates that import, growth rate of GDP, interest rate, first lag of inflation and money supply move positively with the rate of inflation. While other independent variables like exchange rate and fiscal deficit move inversely with inflation. (Bashir et al. 2011) argue that inflation has remained main issue and inconclusive for factors in both fiscal policy and monetary policy perspective. This analysis is conducted on the data from 1972-2006 for inflation using four indicators such as CPI, WPI, SPI and GDP deflator. It is traced out that volume of imports and diminishing in ER play positive contributory role for higher inflation. On contrary, Budget deficit (BD) does not play any role to boost up all signals of inflation (CPI, WPI, SPI, and GDP Deflator).in long run

(Arif and Ali 2012) conduct for Bangladesh on the data used from 1978 to 2010 for applying co-integration error correction techniques for inflation. The study explains that the broad money, import, GDP, and government expenditure have positive effect and export and Government Revenue leave adverse effect for inflation in long run. However, inflation poses Money Supply as a main contributing factor for short run. (Ye et al. 2013) adopt different SIJMB $P$ - ISSN: 2313-1217 E-ISSN: 2410-1885 @ 2015 Sukkur Institute of Business Administration V.2, No.1| Apr 15 
approaches for inflation in China such as L1-Norm $\varepsilon$-Tin Support Vector Regression (L1- $\varepsilon$ - TSVR) which are more powerful than ordinary least square (OLS) and discover the factors of cost-push inflation, where housing sales price index (HSPI) is more significant to others.

There are voluminous studies about the factors of inflation in Pakistan but studies considering total reserves and gross national expenditure as the factors of inflation, as per researchers' knowledge, are lacking. In this way, this paper tries to fill the gap in the literature by additionally considering these two variables.

\section{The Model and Data}

The data set ranges from 1980 to 2012 taken from the State Bank of Pakistan, Pakistan Statistical Bureau, Pakistan Economic Survey, IFS and WDI CD ROM, 2012 pertaining to IMF and World Bank respectively. All data are expressed in base on local, international (\$US) currency and unit less.

(Aljebrin 2006) developed a theoretical model to examine the effect of different macroeconomic variables related to inflation, the model for this study adopts a theoretical frame work as follows:

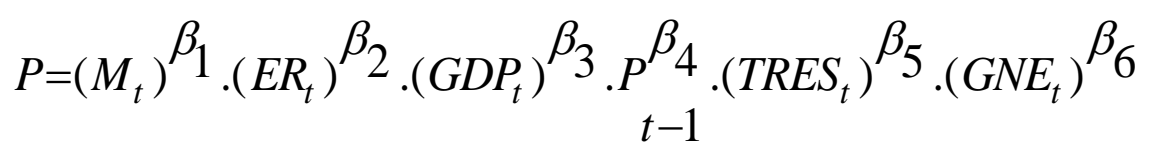

This model can be transformed as

$$
\operatorname{Ln} P_{t}=\beta_{1} \operatorname{Ln}\left(M_{t}\right)+\beta_{2} \operatorname{Ln}\left(E R_{t}\right)+\beta_{3} \operatorname{Ln}\left(G D P_{t}\right)+\beta_{4} \operatorname{Ln}\left(P_{t-1}\right)+\beta_{5} \operatorname{Ln}\left(\operatorname{TRES}_{t}\right)+\beta 6 \operatorname{Ln}\left(G N E_{t}\right)
$$

Where, this model explains CPI as a domestic price level $(\mathrm{P})$, the dependent variable, the broad money supply (M), the exchange rate (ER), gross domestic Product (GDP), first lag in domestic price level ( $\triangle \mathrm{Pt}-1)$, total reserves (TRES), and gross national expenditure (GNE) as independent variables.

In the coming sections, the ARDL Cointegration approach will determine presence between the factors and inflation for long-run relationship which are defined in Eq. (2).

\section{The ARDL Cointegration Approach:}

The autoregressive distributed lag (ARDL) approach is a modern cointegration technique for examining long-run relationships between dependent and independent variables under analysis. This approach is appropriate for small sample size and statistically significant for examining cointegrating relationships in the samples, whereas Johansen cointegration approach needs large sample size for valid findings (Ghatak and Siddiki, 2001). All 
cointegation approaches follow all independent variables to be of the same ordered integrated but ARDL does not demand so. It cancels all pretesting for standard cointigration tests (Pesaran, Shin and Smith, 2001). Moreover, the ARDL is possible for same number of optimal lags, while it is impossible for other traditional models.

In this paper, it is pondered the nascent empirical procedures for examining sources for inflation analysis (Chaudhary et al., 2011). It is assumed that inflation is examined by explanatory determinants such as broad Money supply (M), the exchange rate(ER), Gross Domestic Product (GDP), one lagged Inflation $\left(\mathrm{P}_{\mathrm{t}-1}\right)$ or expected inflation, (TRES) or total reserve and (GNE) Gross national expenditure annually. All variables under study are described in the form of natural logarithmic notation (Ln). The ARDL model described by (Pesaran et al., 2001) is slated as

$$
\begin{aligned}
& \Delta \operatorname{Ln} P=\alpha_{0}+\sum_{i=1}^{n} b_{i} \operatorname{\Delta Ln}\left(M_{t-i}\right)+\sum_{i=1}^{n} c_{i} \Delta \operatorname{Ln}\left(E R_{t-i}\right)+\sum_{i=1}^{n} d_{i} \Delta \operatorname{Ln}\left(G D P_{t-i}\right)+\sum_{i=1}^{n} e_{i} \operatorname{\Delta Ln}\left(P_{t-i}\right)+\sum_{i=1}^{n} f_{i} \operatorname{\Delta Ln}\left(T R E S_{t-i}\right)+\sum_{i=1}^{n} g_{i} \operatorname{LLn}\left(G N E_{t-i}\right) \\
& +\lambda\left(E C M_{t-1}\right)+v_{1 t}
\end{aligned}
$$

The parameter $\lambda_{j}$, where $j=1,2,3,4,5,6$ portrays long run multipliers for corresponding variables, meanwhile the $\mathrm{b}_{\mathrm{i}}, \mathrm{c}_{\mathrm{i}}, \mathrm{d}_{\mathrm{i}}$, and $\mathrm{f}_{\mathrm{i}}$, the indicators of inflation in Pakistan depict, depict short-run multipliers for ARDL model. In ARDL model null hypothesis is stated as (i.e. $H_{0}: \lambda_{1}=\lambda_{2}=\lambda_{3}=\lambda_{4}=\lambda_{5}=\lambda_{6}=0$ ), describing no co-integration) is examined by calculating an F-statistic for all variables expressed in terms of log. Afterwards, one has to compare calculated F- value with the tabulated value prepared by (Pesaran et al. 2001). If calculated F value falls in the right of upper bound the no coinegraiton null hypothesis is rejected, whereas, if it falls below the lower bound it is not rejected. Finally, the result makes indecisive if it is between the bounds.

Eq. (3) has been estimated without the ECM term in start, whereas later it is inculcated in ARDL model as in equation (4)

$$
\begin{aligned}
& \Delta L n P=\alpha_{0}+\sum_{i=1}^{n} b_{i} \Delta L n\left(M_{t-i}\right)+\sum_{i=1}^{n} c_{i} \Delta \operatorname{Ln}\left(E R_{t-i}\right)+\sum_{i=1}^{n} d_{i} \Delta L n\left(G D P_{t-i}\right)+\sum_{i=1}^{n} e_{i} \Delta L n\left(P_{t-i}\right)+\sum_{i=1}^{n} f_{i} \Delta \operatorname{Ln}\left(T R E S_{t-i}\right)+\sum_{i=1}^{n} g_{i} \Delta \operatorname{Ln}\left(G N E_{t-i}\right) \\
& +\lambda\left(E C M_{t-1}\right)+v_{1 t}
\end{aligned}
$$

First data is checked for stationarity due to time series. So, Augmented Dickey Fuller test is applied to examine the stationarity at level and first difference for all the data series in this study. Results are reported in the table- 1 . 
Table1 ADF Unit Root Test Statistics

\begin{tabular}{lllllll} 
Variable & \multicolumn{3}{l}{ Level } & \multicolumn{3}{l}{ first Diff } \\
\hline & intercept & Trend \& intercept & None & intercept & Trend \& intercept & None \\
\hline LP & -2.67 & -2.41 & -0.49 & -4.42 & -4.32 & -4.49 \\
LM & -1.69 & -1.71 & -0.24 & -4.17 & -4.13 & -4.24 \\
LER & -1.8 & -2.11 & 3.05 & -3.69 & -3.73 & -1.91 \\
LGDP & 1.77 & -1.07 & 3.73 & -4.4 & -5.52 & -2.16 \\
LTRES & -0.72 & -1.57 & 0.94 & -3.29 & -3.75 & -3.18 \\
LGNE & -2.45 & -1.54 & 4.33 & -3.93 & -5.53 & -1.29 \\
\hline
\end{tabular}

The critical values at $1 \%, 5 \%$ and $10 \%$ at first difference with intercept, trend $\&$ intercept, and none are[-3.59, -4.17, -2.62]. [-2.93, -3.51, -1.95], and [-2.60, -3.18, -1.61] respectively.

The Table-1 depicts that all variables are statistically significant and with clarity about no unit root with intercept term at first difference.

In ARDL model two is the maximum number of lags selected for data containing 31 data points and computed value of $F$ statistic is found to be 4.75 which lies in the right of upper bound critical value at 5 percent level of significance suggested by (Pesaran et al. 2001). So, null hypothesis can be rejected and it is concluded that there is existence of long run relationship.

Table 2 ARDL $(1,0,1,0,0,1)$ estimated on the basis of AIC and SBC

\begin{tabular}{lllll} 
Variable & Coefficient & Std Error & t-statistic & $\mathrm{p}$-value \\
\hline LP(-1) & -0.801125 & 0.166499 & -4.168195 & 0.0002 \\
LM & -0.061349 & 0.053206 & -1.153058 & 0.2669 \\
LER & -1.081765 & 1.266958 & -0.853829 & 0.4066 \\
LER(-1) & -2.461355 & 1.445513 & -1.702756 & 0.1092 \\
LGDP & 1.104839 & 0.914715 & 1.207815 & 0.2458 \\
LTRES & -0.026169 & 0.192785 & -0.135741 & 0.8938 \\
LGNE & -2.881032 & 2.331667 & -1.235610 & 0.3256 \\
LGNE(-1) & 7.956490 & 2.647150 & 3.005682 & 0.0089 \\
C & -138.3590 & 39.222225 & -3.527563 & 0.0030 \\
\hline & $\mathrm{R}^{2}=0.57$ & $\mathrm{DW}=2.5$ & $\mathrm{~F}=4.75$ & $\mathrm{P}=0.005$
\end{tabular}

Now coefficients for long run relationship are estimated into ARDL model. (Pesaran and Smith 2001) argued that SBC is the best criterion for optimal lag selection for the small sample size as given in this study. Each variable is shown with its optimality of lags as ARDL (1, 0, $1,0,0$, and 1) in the table 2 . 
Table 3 Estimated long-run coefficients through ARDL model

\begin{tabular}{lllll} 
Variable & Coefficient & Std Error & t-statistic & $\mathrm{p}$-value \\
\hline LM & 0.163361 & 0.053788 & 3.037142 & 0.0068 \\
LER & 2.124539 & 0.765465 & 2.775488 & 0.0120 \\
LGDP & 1.375609 & 1.025670 & 1.341180 & 0.1975 \\
LTRES & 0.363482 & 0.159051 & 2.285315 & 0.0340 \\
LGNE & 1.781167 & 1.848406 & 0.963623 & 0.3473 \\
C & -57.52115 & 35.53562 & -1.618690 & 0.1220 \\
\hline & $\mathrm{R}^{2}=0.53$ & $\mathrm{DW}=1.95$ & $\mathrm{~F}=6.53$ & $\mathrm{P}=0.001$ \\
\hline
\end{tabular}

Table 3 shows coefficients of explanatory variables in the long run under the study of this article. The values of coefficients display money supply, exchange rate, gross domestic product, and total reserves push up inflation in Pakistan. Further, the results reveal that on percent increase in exchange rate leads to 2.12 percent rise in the inflation rate. This presents that exchange rate, plays significant role, and most effective source in the inflation of Pakistan.

The empirical findings gesture that one percent increase in import brings to 0.16 per -cent rise in inflation and one percent increase in the exchange rate leads to 2.12 per cent rise in the inflation rate. Similarly, one percent increase in total reserves leads to $0.36 \%$ point increase in the inflation rate at 5\%level of significance.

After the birth of coefficients of long run in ARDL model, it is turn to estimate coefficients of short run through Error Correction Model (ECM), a version of an ARDL model. In table 4 ECM shows the style of adjustment speed of restoration to an equilibrium path in dynamic model. Its coefficient should be negative and statistically significant. Banerjee et al. (1998) proposes that presence of stable long run relationship is further justifiable with highly significant coefficient of ECM.

Table 4 Estimated short run coefficients in ECM

Variables Coefficients Std. Error t-Statistic Prob.

\begin{tabular}{lllll}
\hline LP(-1) & -1.481007 & 0.367117 & -4.034154 & 0.0024 \\
LM & -0.040604 & 0.353231 & -1.616348 & 0.1283 \\
LER & -1.979378 & 1.760685 & -1.616348 & 0.2811 \\
LER(-1) & -3.686655 & 0.794066 & -4.642756 & 0.0002 \\
LGDP & -0.162275 & 0.971546 & -0.167028 & 0.8693 \\
LTRES & 0.149436 & 0.156158 & 0.956951 & 0.3520 \\
LGNE & -2.485476 & 2.426640 & -1.121142 & 0.3231 \\
LGNE(-1) & 6.879294 & 1.561277 & 4.406198 & 0.0004
\end{tabular}




\begin{tabular}{lllll}
$\mathrm{C}$ & -155.5231 & 33.59535 & -4.629305 & 0.0002 \\
$\operatorname{ECM}(-1)$ & -0.805061 & 0.188982 & -4.259992 & 0.0005 \\
\hline & $\mathrm{R}^{2}=0.56$ & $\mathrm{DW}=2.4$ & $\mathrm{~F}=5.79$ & $\mathrm{P}-\mathrm{v}=0.001$
\end{tabular}

The table 4 portrays that the coefficient of ECM with negative sign is a highly significant. The estimated coefficient of the term ECM, is -0.8051 , which suggests that deviation from the long-term inflation path is corrected by around 81 percent over the following year. This means that the adjustment takes place relatively quickly. Alternatively, 81 percent disequilibrium (in inflation) from the previous year shock (in totally all sources) returns back to the long run equilibrium in this year. The coefficient of ECM in the short run and the value of Durbin Watson are found satisfactory.

\section{Plots of the actual and forecasted values for the level of LP and change in LP.}

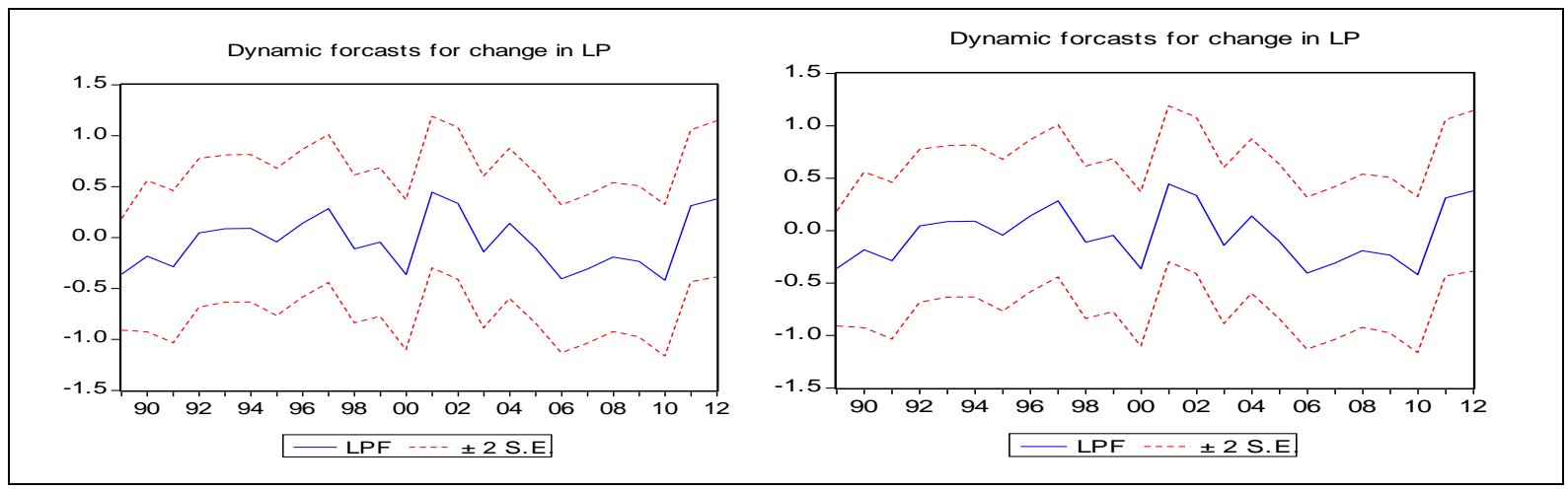

Figure 3

Figure 3 shows the plots of forecasted and actual values for log of inflation rate (LP) and $(\triangle \mathrm{LP})$ change in LP. The plots mentioned in Figure 3 display that historical data follow track very well through this estimated model. Diagnostics for normality, serial correlation, functional form, autocorrelation, and hetroscedasticity are passed by estimated model.

Plots of CUSUM and CUSUMQ statistics for coefficient stability test.
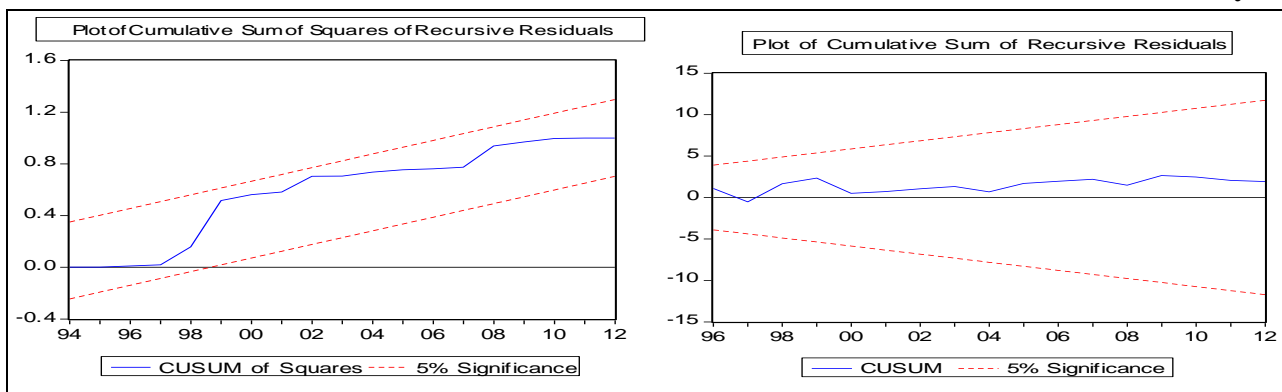

Figure 4 
Figure 4 depicts the CUSUM and CUSUMQ for the stability of forecasting through residuals for Eq. (3). It shows clear evidence for the stability of estimated coefficients in the framed model. Both statistics (CUSUM and CUSUMQ) fall in the confidence interval of $95 \%$ and provide evidence about the stability of parameters within the critical bounds.

\section{Conclusion}

This article uses the annual time series data from 1980 to 2012 to examine main sources of inflation in Pakistan. An Autoregressive Distributed Lag (ARDL) approach is followed for model construction to calculate the coefficients for the short run and long run. The empirical findings suggest the presence of cointegration among the variables considered for this study. Based on the results, the exchange rate plays a significant role in determining inflation as one percent rise in exchange rate invites 2.12 percent rise in inflation. The total reserve affects inflation in the long run while in the short run they don't exert impact on it. Gross national expenditure significantly affects the inflation in the short run while in the long run reports no any impact.

The market and policy makers should pay attention for issues like production system and income distribution that they should not be stagnant. After exchange rate, other sources such as money supply, import, and total reserves are pushing inflation up respectively.

According to the results of this study, one percent rise in money supply invites 0.16 percent points increase in inflation. The results state that one percent rise in liquidity invites $0.16 \%$ points increase in inflation. Following previous reports in Pakistan, budget deficit invites money supply in excess and inflation rises. So, monetary and fiscal institutions should be independent to control the exchange rate and budget deficit. Moreover, this positive correlation between inflation and exchange rate suggests that instability in exchange rate causes havoc in exchange market and lowers the inflation.

At the end, the ECM part of an ARDL model depicts the coefficient of Error Correction is highly significant and negative in sign. The findings portrays that the deviation from equilibrium in the long run for inflation is adjusted approximately 81percent in the current year. The all diagnostics and plots performance (CUSUM and CUSUMQ plots) posits the stability of coefficients estimated in the model for both short run and long run in the sample of the study.

The main factors of inflation are money supply, total reserve, imports, gross domestic product, and gross national expenditure that can be considered for the large sample size with maximum frequency in the future. 


\section{References}

Abidemi, O. I. and Malik, S. A. A. (2010). Analysis of Inflation and its determinant in Nigeria.Pakistan Journal of Social Sciences, 7(2), 97 - 10

Alderman, H. (2005). Linkages between poverty reduction strategies and child nutrition: An Asian perspective. Economic and Political Weekly, 4837-4842.

Aljebrin, M. (2006) Analysis of Inflation in Determinants Developing Oil Export Based Economies, Doctoral dissertation,Colorado State University, Fort Collins, Colorado.

Arif, K. M., \& Ali, M. M. (2012). Determinants of Inflation in Bangladesh: An Empirical Investigation. Journal of Economics and Sustainable Development, 3(12), 9-17.

Asian Development Bank, report, (2012).

Bashir, M. F., Nawaz, M. S., Yasin, M. K., Khursheed, M. U., Khan, M. J., \& Qureshi, M. M. J. (2011). Determinants of Inflation in Pakistan: An Econometric Analysis using Johansen Co-Integration Approach. Australian Journal of Business and Management Research Vol, 1(5), 71-82.

Banerjee, A., Dolado, J., \& Mestre, R. (1998). Error-correction mechanism tests for cointegration in a single-equation framework. Journal of time series analysis, 19(3), 267-283.

Chaudhary,et'ai (20110. Foreign Exchange Reserves and Inflation in Pakistan: Evidence from ARDL Modelling Approach. International Journal of Economics and Finance Vol. 3, No. 1; February 2011

Easterly, W. (2003). IMF and World Bank structural adjustment programs and poverty. In Managing currency crises in emerging markets (pp. 361-392). University of Chicago Press.

Ghatak S. and Siddiki, J. (2001) The Use of ARDL Approach in Estimating Virtual Exchange Rates in India, J. Applied Statistics, 28:573-58.

Hussain, M. (2005). Inflation and Growth: Estimation of Threshold Point for Pakistan. Economic Policy Department, State Bank of Pakistan, October.

Khan, M., \& Schimmelpfennig, A. (2006). Inflation in Pakistan: Money or wheat?

Keran, M. W., \& Al Malik, A. A. (1979). Monetary sources of inflation in Saudi Arabia. Federal Reserve Bank of San Francisco.

Khan, R. E. A., \& Gill, A. R. (2010). Determinants of Inflation: A Case of Pakistan (1970007). Journal of Economics, 1(1), 45-51.

Hasan, M., \& Alogeel, H. (2008). Understanding the inflationary process in the GCC region: The case of Saudi Arabia and Kuwait (No. 2008-2193). International Monetary Fund. 
Laryea, S. A., \& Sumaila, U. R. (2001). Determinants of inflation in Tanzania. Chr. Michelsen Institute.

Pahlavani, M., \& Rahimi, M. (2009). Sources of Inflation in Iran: An application of the ARDL Approach. International Journal of Applied Econometrics and Quantitative Studies, 6(1), 6176.

Papi, L., \& Lim, C. H. (1997). An econometric analysis of the determinants of inflation in Turkey.

Pesaran, M.H., Shin, Y., Smith, R.J., (2001) Bounds Testing Approaches to the Analysis of Level Relationships. Journal of Applied Econometrics 16, 289-326.

Selden, R. T. (1959). Cost-push versus demand-pull inflation, 1955-57. The Journal of Political Economy, 1-20.

Sharif, M. Umar.\& Bashir, Arshad (2000). Illegal trade of Pakistan with Afghanistan and Iran through Balochistan: Size, balance and loss to the public exchequer. International Journal of Agriculture and Biology, 2(3), 199-203.

Taslim, M. A., 1980, 'Inflation in Bangladesh: A Re-examination of the Structuralist Monetarist Controversy'.The Bangladesh Development Studies, X (1), 100-116

Ye, Y. F., Cao, H., Bai, L., Wang, Z., \& Shao, Y. H. (2013). Exploring Determinants of Inflation in China based on $\langle\mathrm{i}>\mathrm{L}</ \mathrm{i}>1-<\mathrm{i}\rangle \in</ \mathrm{i}\rangle$-Twin Support Vector Regression. Procedia Computer Science, 17, 514-522. 